\title{
Human Papillomavirus Positive
}

National Cancer Institute

\section{Source}

National Cancer Institute. Human Papillomavirus Positive. NCI Thesaurus. Code C128839.

Indicates that human papillomavirus has been detected in a sample. 